\title{
Cost comparison of Licensed Shared Access (LSA) and MIMO scenarios for capacity growth in Finland
}

\author{
Michail Katsigiannis, Arturo Basaure \\ Department of Communications and Networking \\ Aalto University, School of Electrical Engineering \\ Helsinki, Finland \\ \{michail.katsigiannis, arturo.basaure\}@aalto.fi
}

\author{
Marja Matinmikko \\ VTT Technical Research Centre of Finland \\ Oulu, Finland \\ Marja.Matinmikko@vtt.fi
}

\begin{abstract}
The high mobile data traffic growth requires investments in radio access networks. Network capacity expansion can be achieved by increasing the number of base stations, increasing the network spectral efficiency and obtaining additional spectrum. This study assumes a constant number of base station to compare two potential future network deployment scenarios; the Licensed Shared Access scenario (LSA), which adds spectrum to the network and a Multi-Input and MultiOutput (4x2 MIMO) antenna technology, which increases the network's spectral efficiency. Both deployment scenarios are studied for the urban regions in Finland. The purpose is to examine the spectrum availability and evaluate under which conditions LSA is more likely to be implemented in the Finnish market. With the assumptions taken, the results show that the LSA scenario provides more capacity but the MIMO scenario provides a more cost efficient alternative. The MIMO technology is preferable than a LSA deployment for mobile data traffic growth rate less than 2.7. For larger growth rate (up to 3.5) the LSA scenario is a feasible solution either as independent or complementary technique.
\end{abstract}

Keywords-Licensed Shared Access; MIMO; spectrum; mobile data traffic; techno-economics; costs; urban region; Finland

\section{INTRODUCTION}

Under the highly anticipated exponential growth in mobile data traffic, mobile network operators (MNOs) should deploy different strategies to attain higher level of efficiency in their networks. From a general perspective, MNOs can invest in upgrading their networks or may alternatively deploy emerging dynamic spectrum access (DSA) technologies to obtain additional spectrum capacity. This paper compares a next possible step for these two evolution paths. From one side, this study investigates the case of Licensed Shared Access (LSA), which is a mechanism which facilitates MNOs to obtain additional spare spectrum from other spectrum holders. On the other side, this paper studies the deployment of 4x2 MIMO (Multiple-Input and Multiple-Output) smart antenna technology, which is likely to be deployed by MNOs in the near future to boost their network performance. Both deployment scenarios are studied for the case of Finland.

The purpose of this paper is to evaluate whether Licensed Shared Access is worth being implemented. The paper performs a quantitative analysis for a Finnish MNO. Firstly it examines the spectrum availability and needs. Secondly, the cost of a LSA scenario is compared to the deployment of $4 \times 2$
MIMO smart antenna technology. In this way, the paper compares the effect of bringing additional spectrum to MNO's networks against increasing their spectral efficiency. The paper aims to answer to the following question: "under which conditions is LSA more likely to be implemented in the Finnish market?" To answer this research question, a cost model is developed to investigate the network cost over any data traffic growth in near future for the urban regions in Finland. The future investments are based on the existing network infrastructure, assuming that the number of sites remains unchanged. The main outputs of the model are the capital and operating costs as well as the cost unit curves (average and marginal cost) which will provide the essential information for decision-making.

This paper contributes to assess the potential benefits of two alternative solutions for attending the increasing demand of mobile markets in the short term. The paper investigates real cases for mobile operators, and provides useful information for decision making in network evolution. In concrete, this study explores the Finnish market, so that conclusions can be easily employed to other larger markets as well.

The paper is outlined as follows: Section II discusses the spectrum availability and potential future allocated spectrum to a Finnish MNO, as well as the LSA concept. Section III describes the model. Section IV covers the results of the model. The paper is concluded in Section V.

\section{SPECTRUM AND LiCENSED SHARED ACCESS (LSA)}

\section{A. Spectrum}

Currently, the licensed bands allocated by the Finnish regulatory authority FICORA for mobile communications to provide national coverage add up to $555 \mathrm{MHz}$. The amount of spectrum which has been harmonized by the European Conference of Postal and Telecommunications Administrations (CEPT) is $1077 \mathrm{MHz}$, but it is not fully utilized by mobile communications industry. Table I presents the spectrum bands for International Mobile Telecommunications (IMT) in Europe and Finland determined by International Telecommunication Unit (ITU), CEPT and FICORA [1-4]. In addition, the Table II shows the current and the potential future allocated spectrum in average for a Finnish MNO [3, 5]. The candidate band for potential use of LSA in Europe is at $2300 \mathrm{MHz}$. The total spectrum identified for IMT in this frequency band is 100 
MHz. Initial studies [6] suggest the share of spectrum dedicated for downlink to be 0.75 and the guard gaps between networks $10 \mathrm{MHz}$. Also, the spectrum which would be available for MNO from the incumbent is used for $90 \%$ of the time. Thus, for the Finnish market with three existing operators, the potential assigned spectrum for one operator in this band is $0.75 *(100-2 * 10) * 0.9 / 3=18 \mathrm{MHz}$.

TABLE I. IMT SPECTRUM BANDS (MHZ)

\begin{tabular}{|c|c|c|c|}
\hline Bands & $\begin{array}{c}\text { Bands } \\
\text { identified by } \\
\text { ITU for IMT } \\
\text { in Europe }\end{array}$ & $\begin{array}{c}\text { CEPT harmonized } \\
\text { band for mobile in } \\
\text { Europe }\end{array}$ & $\begin{array}{l}\text { Licensed bands } \\
\text { allocated by } \\
\text { FICORA }\end{array}$ \\
\hline 450 & $\begin{array}{c}450-470 \\
\left(\mathrm{WRC}^{\prime} 07\right)\end{array}$ & - & - \\
\hline 700 & $\begin{array}{c}694-790 \\
\text { (WRC'12/15) }\end{array}$ & - & - \\
\hline 800 & $\begin{array}{c}900-862 \\
(\text { WRC'07) } \\
\end{array}$ & $790-862$ & $\begin{array}{c}\text { FDD 2x30: } \\
791-821 / 832-862\end{array}$ \\
\hline 900 & $\begin{array}{c}862-960 \\
(\text { WRC' } 00)\end{array}$ & $\begin{array}{c}\text { FDD 2x35: } \\
880-915 / 925-960 \\
\end{array}$ & $\begin{array}{c}\text { FDD 2x35: } \\
880-915 / 925-960 \\
\end{array}$ \\
\hline 1400 & - & $1452-1492$ & - \\
\hline 1800 & $\begin{array}{l}1710-1885 \\
(\text { WRC '00) }\end{array}$ & $\begin{array}{l}\text { FDD 2x75: 1710- } \\
\text { 1785 / 1805-1880 }\end{array}$ & $\begin{array}{l}\text { FDD 2x75:1710- } \\
1785 / 1805-1880\end{array}$ \\
\hline \multirow{2}{*}{2100} & \multirow{2}{*}{$\begin{array}{l}1885-2025, \\
2110-2200 \\
\text { (WARC'92) }\end{array}$} & \multirow{2}{*}{$\begin{array}{c}\text { FDD 2x60, TDD 35: } \\
\text { 1900-1980, 2010- } \\
2025,2110-2170\end{array}$} & $\begin{array}{l}\text { FDD 2x60: } 1920- \\
\text { 1980/2110-2170 }\end{array}$ \\
\hline & & & $\begin{array}{c}\text { TDD 15: 1900- } \\
1910,1915-1920 \\
\end{array}$ \\
\hline 2300 & $\begin{array}{l}2300-2400 \\
(\text { WRC '07) } \\
\end{array}$ & - & - \\
\hline 2600 & $\begin{array}{l}2500-2690 \\
(\text { WRC '00) } \\
\end{array}$ & $\begin{array}{c}\text { FDD } 2 \times 70, \text { TDD 50: } \\
2500-2690 \\
\end{array}$ & $\begin{array}{l}\text { FDD 2x70: } 2500- \\
2570 / 2620-2690 \\
\end{array}$ \\
\hline 3500 & $\begin{array}{l}3400-3600 \\
(\text { WRC '07) } \\
\end{array}$ & $3400-3600$ & - \\
\hline 3700 & - & $3600-3800$ & - \\
\hline Total & $1181 \mathrm{MHz}$ & $1077 \mathrm{MHz}$ & $555 \mathrm{MHz}$ \\
\hline
\end{tabular}

TABLE II. ALLOCATED SPECTRUM FOR A FINNISH OPERATOR (MHZ)

\begin{tabular}{|c|c|c|}
\hline \hline Bands & $\begin{array}{c}\text { Current allocated } \\
\text { spectrum (2014) }\end{array}$ & $\begin{array}{c}\text { Potential future allocated } \\
\text { spectrum (2020) }\end{array}$ \\
\hline $\mathbf{4 5 0}$ & - & - \\
\hline $\mathbf{7 0 0}$ & - & FDD $2 \times 10$ \\
\hline $\mathbf{8 0 0}$ & FDD $2 \times 10$ & FDD $2 \times 10$ \\
\hline $\mathbf{9 0 0}$ & FDD $2 \times 11.4$ & FDD $2 \times 11.4$ \\
\hline $\mathbf{1 4 0 0}$ & - & TDD 15 \\
\hline $\mathbf{1 8 0 0}$ & FDD $2 \times 24.8$ & FDD $2 \times 24.8$ \\
\hline \multirow{2}{*}{2100} & FDD $2 \times 19.8$ & FDD $2 \times 19.8$ \\
\cline { 2 - 3 } & TDD 4.8 & TDD 4.8 \\
\hline $\mathbf{2 3 0 0}$ & - & TDD 18 \\
\hline \multirow{2}{*}{$\mathbf{2 6 0 0}$} & FDD $2 \times 25$ & FDD $2 \times 25$ \\
\cline { 2 - 3 } & - & TDD 10 \\
\hline $\mathbf{3 5 0 0}$ & - & - \\
\hline $\mathbf{3 7 0 0}$ & - & - \\
\hline Total & $186.8 \mathrm{MHz}$ & $249.8 \mathrm{MHz}$ \\
\hline \hline
\end{tabular}

\section{B. Licensed Shared Access (LSA) concept}

To help the regulators to take into use more of these IMT bands for mobile communications, spectrum sharing under the new Licensed Shared Access (LSA) concept is under study in regulation and research [7]. The LSA concept would allow the incumbent spectrum users to maintain their rights while a limited number of additional users, here MNO, would be granted a license to access the band when it does not cause harmful interference to the incumbent. LSA represent a first step to perform spectrum transactions with a guaranteed quality of service through a legal contract providing certainty and potentially financial compensation. For a MNO, it is the most concrete means to increase the required network capacity by employing DSA technologies.

\section{MODEL}

The model for evaluating the business potential of new techniques to improve the capacity focuses on a single MNO in Finnish market for urban regions. The inputs of the model are grouped to i) market and service, ii) technology and spectrum and iii) cost in the second half of 2013 (Fig. 1). The servicerelated inputs are the total volume of data traffic [8] and its characteristics such as uplink to downlink ratio [9], traffic distribution for busy hour [10] and traffic distribution among sites [11]. The market is defined in terms of geographical area i.e., urban regions [12-13] and market share [14]. Regarding the technology-related input parameters, the technical architecture is defined by network technologies [6, 15], territory and population coverage percentages [16-20], and assumptions about the network configuration. For each network technology the typical spectrum efficiency [21-22], the average cell range [21] and the current coverage rollout are specified. Some additional design parameters are also assumed to calculate the number of sites and other radio access network entities [23-25]. Finally, the power consumption parameters for each base station type are also included [26-27]. The spectrum parameters include the spectrum availability [3] and assumptions about the spectrum share between data and voice services. The main cost parameters include the list and the price of the radio access network equipment and sites, the network implementation actions and operational expenditures [6, 23-25]. The important input parameters and their numerical values can be found in Tables A.1 - 6 in Appendix.

The outputs of the model are the average cell spectrum and the spectral efficiency for the future network deployment scenarios as well as their cost curves; the investment cost (CAPEX), operating cost (OPEX), and the marginal and average cost. The evolved network assumes that the number of sites remains the same, after an initial network investment for deploying Long Term Evolution (LTE) network at $1800 \mathrm{MHz}$ and the Evolved High-Speed Packet Access (HSPA+) network (Release 10, quad carrier-QC) for the whole urban regions. Then, based on this infrastructure, the two alternative scenarios are compared. The assumptions for the network deployment are the followings:

1. LTE 1800 \& HSPA QC: An initial investment scenario which includes LTE network expansion and (HSPA+) multi carrier with adjacent channels. Dual band eNodeBs at 1800 and $2600 \mathrm{MHz}$ are installed on the existing GERAN1800 sites, replacing the BTSs (GSM remains due to Multi Standard Radio feature). Also, carriers are added to the NodeBs at $2100 \mathrm{MHz}$. (UTRAN 3 and E-UTRAN 1-2 in Table A.3 in Appendix A). 


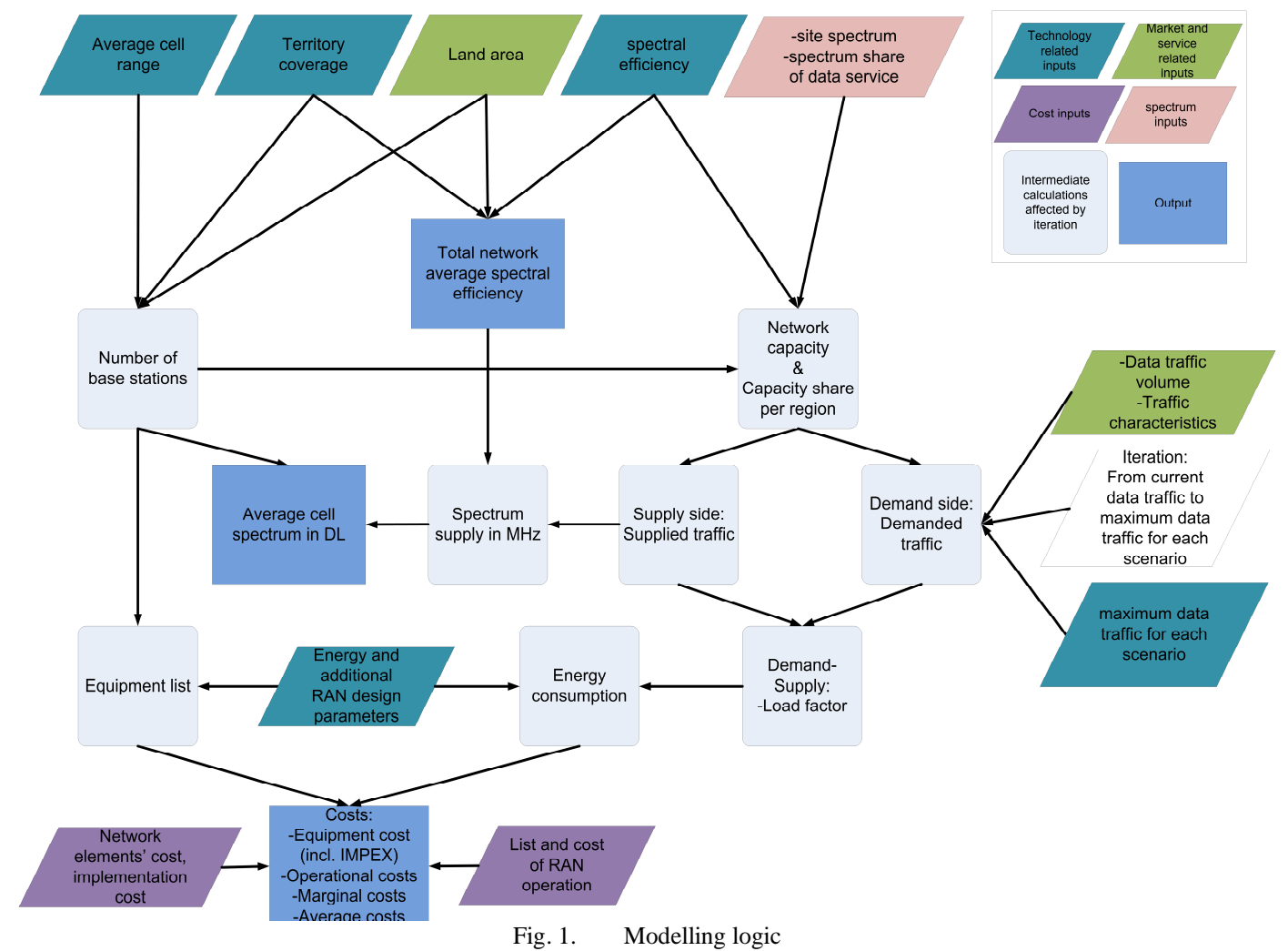

2. LSA: LSA-capable eNodeBs are installed to the sites with eNodeBs replacing the old base stations. (E-UTRAN 3-4 in Table A.3 in Appendix A).

3. $4 \times 2$ MIMO: MIMO antenna system is installed to the sites with NodeBs and eNodeBs (E-UTRAN 5-6 and UTRAN 4 in Table A.3 in Appendix A).

For any investment scenario, the model investigates how the cost and other results are progressed over any data traffic growth which can be carried in each scenario. In this way, the model does not incorporate any forecasts about service penetration, mobile data traffic volume, data users and/or average user data rates, i.e., the model is indifferent how the data traffic increases. This makes the model robust to data traffic growth assumptions, since a lot of uncertainties which are related to demand estimation are removed.

\section{RESULTS}

Fig. 2 illustrates different combinations of average spectrum per cell and average spectral efficiency to mobile data traffic growth. The indifference curves (or isoquants) represent the mobile data traffic. The current network infrastructure (green square) lays on the indifferent curve with mobile data traffic growth of 1.1. This means that the current network operates almost at its full capacity but there is some room for unexpected additional traffic to avoid a sudden potential congestion. The initial investment for LTE1800 \& HSPA QC deployment increases both the spectral efficiency and the average cell spectrum (black square). This network deployment increases the network capacity which can carry 2.3 times more data traffic. Then, the two alternative options are compared; LSA and 4x2 MIMO. Both scenarios are compared at the end of the projects where all the sites have been equipped with the corresponding network elements. The LSA scenario adds extra spectrum in cells whereas the spectral efficiency is constant (from black to blue square). In contrary, the MIMO scenario keeps the average spectrum per cell constant, but the spectral efficiency increases significantly (from black to red square). The LSA scenario can provide more capacity and carry 2.9 times more mobile data traffic, compared to MIMO scenario which can carry 2.7 times more traffic than the current network. In this analysis, the LSA scenario seems to be preferable than the MIMO scenario. However the difference is rather small. Finally, the Fig. 2 illustrates the case of a network with combined LSA and MIMO deployment, in which the traffic capacity is increased by 3.5 times.

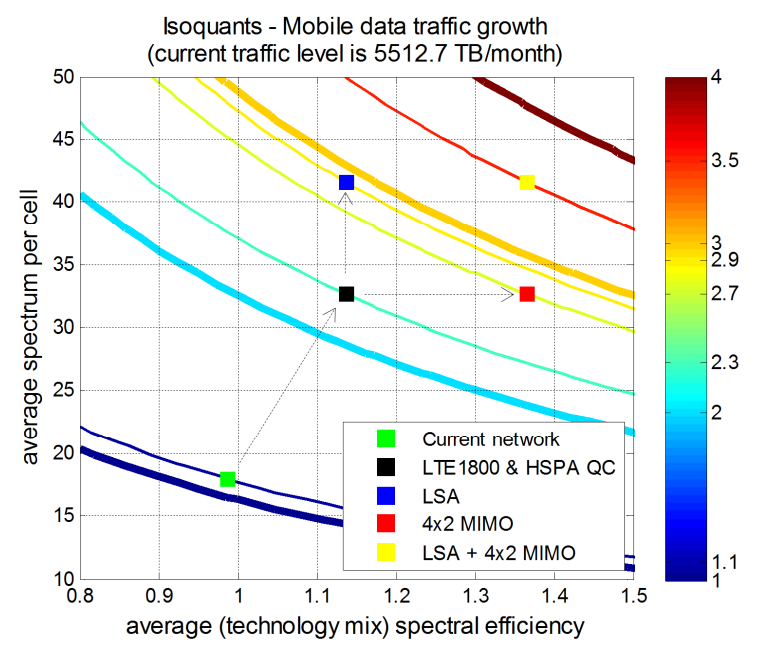

Fig. 2. Network deployments and isoquants for mobile data traffic. 
a. Investment cost (annualized in y years)

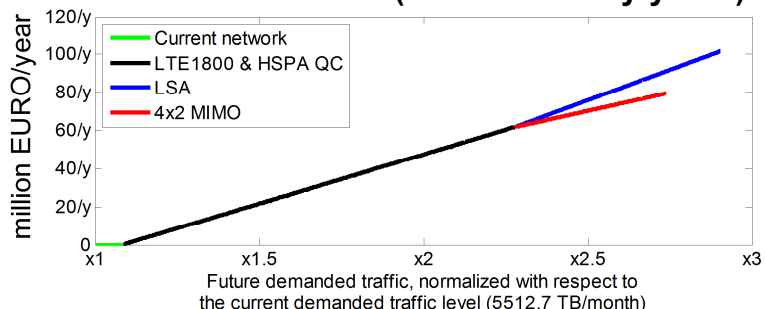

c. Unit cost curves $(y=3.5)$

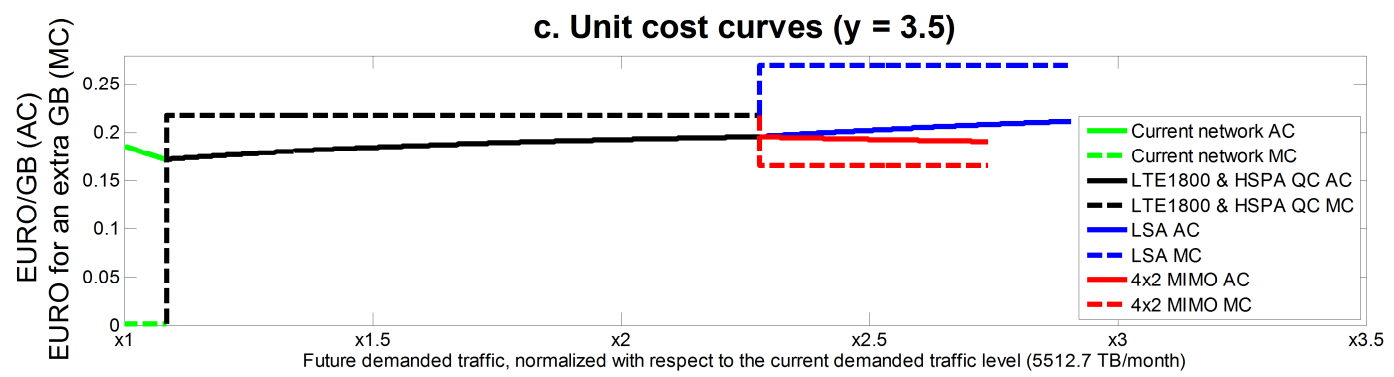

Fig. 3. Cost results for the network evolution

Fig. 3 shows the cost results which include the investment cost, the annual operating cost and the marginal and average cost for mobile data traffic. The horizontal axis shows the network capacity in the form of traffic growth rate. The Fig. 3a depicts the investment or capital cost. The investment cost curves increase linearly until all equipment is installed for all scenarios. Firstly, for the current network (green line), the investment cost is zero until the traffic grows 1.1 times. Then the network capacity grows up to 2.3 times with the deployment of LTE 1800 \& HSPA QC networks (black line). Finally, the two cost lines represent LSA and MIMO scenarios (blue line and red line respectively). For a given traffic growth above 2.3, the LSA scenario has higher investment cost than MIMO. However, as also mentioned above, the maximum demanded traffic which is able to be carried is greater for LSA.

The Fig. 3b shows the operating costs. The difference between LSA and MIMO cost curves can be explained by energy consumption and the maintenance cost. The maintenance cost is proportional to the number of network components. The number of network elements for MIMO scenario is larger, because the MIMO antenna system is installed to the sites which are equipped with UTRAN. The number of these sites is bigger than the number of sites which are equipped with E-UTRAN. Regarding the energy cost, it decreases for the initial investments because of the more energy efficient eNodeB in conjunction to the replacement of the legacy GERAN's BTS sites. At the maximum network capacity for LSA and MIMO scenarios, the energy consumption is 1.99 and $2.1 \mathrm{GWh} /$ month respectively.

Finally, the Fig. 3c illustrates the unit cost curves. The calculation of the marginal and average cost for each scenario requires the investment cost to be annualized in years y and added to operating costs (e.g., $y=3.5$ years which corresponds to the first half of 2017). The marginal costs are constant and higher than the average total cost for the initial investment and the LSA scenario. In these cases, the average cost is increasing, indicating diseconomies of scales. On the contrary, MIMO scenario possesses a lower marginal cost than average cost. The marginal analysis is a significant managerial tool for b. Operating cost

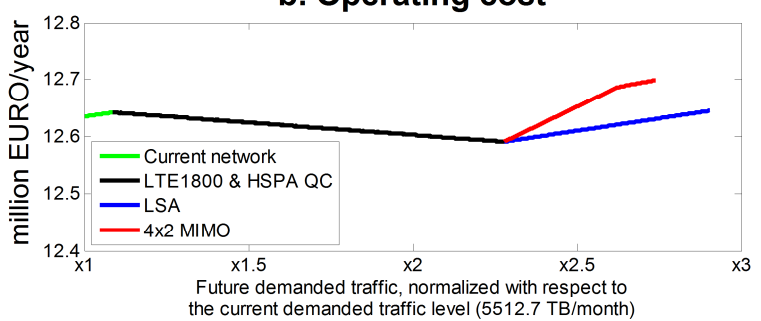

3

\section{.}

optimal decision making; the optimum and cost-efficient scenario is the one with the lowest marginal cost. It is derived that the $\mathrm{MC}_{\mathrm{LSA}}>\mathrm{MC}_{\mathrm{MIMO}}$ over the additional demanded traffic. The marginal cost (cost of producing one more GB) for LSA scenario is $\mathrm{MC}_{\mathrm{LSA}}=0.27 €$, whereas for the MIMO scenario $\mathrm{MC}_{\mathrm{MIMO}}=0.166 €$. Therefore, the MIMO scenario is economically preferable because the increase of production by one more unit costs less. However, considering that LSA can carry more traffic, the tradeoff between the project durability (e.g., higher parameter y for LSA) and the cost needs to be evaluated.

The Table III presents the most important numerical results for the current and future networks. The numerical results for the parameters are shown for the maximum traffic which can be carried in each network deployment scenario.

TABLE III. NUMERICAL RESULTS

\begin{tabular}{|c|c|c|c|c|}
\hline Parameter & $\begin{array}{l}\text { Current } \\
\text { network }\end{array}$ & $\begin{array}{c}\text { LTE1800 \& } \\
\text { HSPA QC }\end{array}$ & LSA & $\begin{array}{c}4 \times 2 \\
\text { MIMO }\end{array}$ \\
\hline Data traffic growth & 1.11 & 2.3 & 2.9 & 2.7 \\
\hline $\begin{array}{l}\text { Average cell spectrum } \\
\text { for data (MHz) }\end{array}$ & 17.9 & 32.65 & 41.61 & 32.65 \\
\hline $\begin{array}{c}\text { Spectrum efficiency } \\
(\mathrm{bps} / \mathrm{Hz})\end{array}$ & 0.988 & 1.14 & 1.14 & 1.37 \\
\hline Investment cost ( $\left.€^{\prime} \cdot 000\right)$ & - & 61,797 & 101,697 & 79,497 \\
\hline $\begin{array}{c}\text { Operating cost } \\
(€ \cdot 000 / \text { year })\end{array}$ & 12,642 & 12,591 & 12,645 & 12,699 \\
\hline $\begin{array}{c}\text { Marginal cost ( } € \text { for an } \\
\text { extra GB/month) }\end{array}$ & 0.0012 & 0.218 & 0.27 & 0.166 \\
\hline $\begin{array}{c}\text { Average total cost } \\
(€ / G B)\end{array}$ & 0.172 & 0.196 & 0.212 & 0.191 \\
\hline $\begin{array}{l}\text { Average cost per site } \\
(€ / \text { site/month })\end{array}$ & 757 & 1810 & 2495 & 2119 \\
\hline $\begin{array}{c}\text { Energy consumption } \\
(\mathrm{GWh} / \mathrm{month})\end{array}$ & 2.08 & 1.91 & 1.99 & 2.1 \\
\hline Energy cost share (\%) & 7.9 & 7.3 & 7.6 & 7.9 \\
\hline
\end{tabular}




\section{Discussion AND CONSLUSIONS}

The mobile operators need to evolve their radio access networks to carry the future data traffic volume. The paper intends to solve the decision problem of mobile operators on the evolution of their radio access networks, by using economic theory and cost modeling. Cost analysis is conducted to provide information on the scale (capacity end coverage) of the radio access networks and show which is the most preferable scenario for the network capacity expansion for Finnish urban regions. Network capacity expansion can be occurred by increasing the number of base stations, increasing the network spectral efficiency and use additional spectrum. Assuming that the number of base station is constant for a dense network infrastructure, this study investigates and compares two potential future network deployments; the LSA scenario, which add spectrum to the network and the $4 \times 2$ MIMO antenna technology scenario, which increases the network's spectral efficiency. Prior to the comparison of these two scenarios, the study assumes a LTE 1800 and HSPA+ R10 QC deployment. As a result, the paper shows that the LSA scenario provides more capacity but the MIMO scenario provides a more cost efficient alternative. The LSA can carry traffic up to 2.9 times more than the current traffic and the cost transmitting one extra GB per month is $0.27 €$, whereas the corresponding numbers for MIMO scenario are 2.7 and $0.17 €$.

In general terms, the MIMO technology is more costefficient and preferable than a LSA deployment for the near future network evolution. In addition, Finland is not lacking spectrum at this moment. In fact, the future auction of the second part of digital dividend band $(700 \mathrm{MHz})$ will provide additional $30 \mathrm{MHz}$ for mobile services. Besides spectrum, the state-of-the-art of the technology (such as, MIMO smart antenna technologies) may be firstly utilized before make any use of dynamic spectrum mechanism such as LSA which requires additional effort for regulation. In conclusion, based on model assumption for urban regional network in Finland, the MIMO scenario is better solution for mobile data traffic growth rate less than 2.7. For larger growth rate (up to 3.5) the LSA scenario is a feasible solution either as independent or complementary technique

In the longer run, when the network has reach its limits for capacity, network infrastructure and the antenna systems density, new network deployment scenarios need to be investigated; i) LTE-Advanced with carrier aggregation and HSPA+ multicarrier and multiband. The spectrum can be aggregated utilizing all available bands, including licenseexempt spectrum for LTE-Wi-Fi carrier aggregation. Also LSA can enable additional spectrum to be aggregated ii) higher order of MIMO (e.g., 8x8 MIMO) and active antennas, iii) higher order of vertical and horizontal sectorization, iv) installation of outdoor small cells and/or relays, v) other techniques such as coordinated multipoint (eCOMP) and baseband pooling. Other disruptive technologies which introduces also the $5 \mathrm{G}$ era are millimeter-wave technologies, massive MIMO, new modulation schemes with high spectral efficiencies and extreme network densification with small cells. Finally, another further research could perform a similar analysis for other countries or larger markets in order to observe potential similarities.

\section{REFERENCES}

[1] International Telecommunication Union, "Frequency arrangements for implementation of the terrestrial component of International Mobile Telecommunications (IMT) in the bands identified for IMT in the Radio Regulations (RR)", ITU-R, Geneva, M series recommendation, M.10364, March 2012.

[2] Electronic Communications Committee, "The European table of frequency allocations and applications in the frequency range $8.3 \mathrm{kHz}$ to $3000 \mathrm{GHz}$ (ECA table)”, ERC report 25, May 2014.

[3] European Communications Office, "The Licensing of Mobile Bands in CEPT”, ECO report 03, June 2014.

[4] ECO Frequency Information System [online]. Available at: http://www.efis.dk/views2/search-general.jsp

[5] European Commission, "RSPG opinion on strategic challenges facing Europe in addressing the growing spectrum demand for wireless broadband", Radio Spectrum Policy Group, Brussels, RSPG13-521 rev1, June 2013.

[6] T. Lavender, P. Marks and S. Wongsaroj, "The economic benefits of LSA in $2.3 \mathrm{GHz}$ in Europe", Plum Consulting, report for Ericsson, NSN and Qualcomm, London, December 2013.

[7] European Commission, EU COM (2012) 478. (2012). European Economic and Social Committee, "Promoting the shared use of radio spectrum resources in the internal market", Brussels, September 2012. [online]. Available at: http://ec.europa.eu/digital-agenda/sites/digitalagenda/files/com-ssa.pdf

[8] Finnish Communications Regulatory Authority (2014, March 10), Mobile data transmission volume, [online]. Available at: https://www.viestintavirasto.fi/en/aboutthesector/statistics/internetandtel ephone/mobiledatatransmissionvolume.html

[9] P. Marks, D. Black and D. Lewin, "Mobile traffic is highly asymmetric", in Economic study of the benefits from use of 1452-1492 $\mathrm{MHz}$ for a supplemental mobile downlink for enhanced multimedia and broadband services, Plum Consulting, report for Ericsson and Qualcomm, London, June 2011, pp.17-18.

[10] H. Holma and A. Toskala, "Performance", in LTE for UMTS - OFDMA and SC-FDMA Based Radio Access, John Wiley \& Sons Ltd, United Kingdom, 2009, pp. 213 - 257.

[11] Nokia Siemens Networks, "Mobile broadband with HSPA and LTE capacity and cost aspects", Espoo, 2010.

[12] Official Statistics of Finland (2013, December 31), Population structure, [online]. Available at: http://www.stat.fi/til/vaerak/tau_en.html

[13] Official Statistics of Finland (2010), Group of municipalities, [online]. Available at: http://www.stat.fi/meta/luokitukset/kuntaryhmitys/0012010/luokitusavain_teksti.txt

[14] Finnish Communications Regulatory Authority (2014, March 11), Market shares of mobile subscriptions, [online]. Available at: https://www.viestintavirasto.fi/en/aboutthesector/statistics.html

[15] 3rd Generation Partnership Project, "Technical Specification Group Services and System Aspects, Network architecture", TS 23.003, Release 11.

[16] DNA (2013), press releases, [online]. Available at: https://www.dna.fi/en/press-releases.

[17] DNA (2013), coverage map, [online]. Available at: http://kuuluvuus.dna.fi/Peittokartta_en/mapviewer.jsf?width=300\&heigh $\underline{\mathrm{t}=300 .}$.

[18] Elisa (2013), press releases, [online]. Available at: http://corporate.elisa.com/press-releases/

[19] Elisa (2013), coverage map, [online]. Available at: http://elisa.fi/kuuluvuus

[20] Teliasonera (2013), press releases, [online]. Available at: http://www.teliasonera.com/en/newsroom/press-releases/

[21] Holma, H. and Toskala, A. (2011), "Performance", LTE for UMTS: Evolution to LTE-Advanced, Second Edition, John Wiley \& Sons Ltd, United Kingdom, 2011, pp. $257-301$.

[22] Real Wireless (2011, January 27), “4G Capacity Gains. Final report for Ofcom", report for Ofcom, United Kingdom, [online]. Available at: 
http://www.apwpt.org/downloads/ofcommay2011_4gcapacitygainsfinalr eport_main.pdf

[23] Norwegian Post and Telecommunications Authority (2013, March 14), "LRIC for mobile networks". Reports from Analysys Mason, [online] Available at: http://eng.npt.no/market/market-regulation-smp/costmodel//ric-for-mobile-networks

[24] National Post and Telecom Agency PTS (2011, May 16), "New mobile long-run incremental cost (LRIC) model. Documentation for the final cost model", report from Analysys Mason, [online]. Available at: https://www.pts.se/upload/Remisser/2011/Telefoni/10-8320-finalmodel-with-tracks-mobile.pdf

[25] Ofcom (2010), "Long-run incremental cost (LIRC) model, [online]. Available at: http://www.ofcom.org.uk/static/wmctr/

[26] A. Conte, "Power consumption of base stations", Trend Plenary meeting for Seventh Framework Programme, Ghent, 2012, February 14-15, Alcatel-Lucent Bell Labs, France.

[27] M. Katsigiannis and H. Hämmäinen, "Energy consumption of radio access networks in Finland", Telecommunication Systems, vol. 55, no. 2, pp. 241-251, February 2014.

\section{APPENDIX - INPUT VARIABLES}

\section{1) Market and service related inputs}

TABLE A.1. BASIC DEMOGRAPHICS FOR URBAN REGIONS

\begin{tabular}{|c|c|}
\hline Land (km2) & 1166 \\
\hline Population & 1757959 \\
\hline Population density & 1507 \\
\hline Territory percentage (\%) & 0.39 \\
\hline Population percentage (\%) & 32.22 \\
\hline
\end{tabular}

TABLE A.2. MOBILE MARKET AND SERVICE CHARACTERISTICS (2H/2013)

\begin{tabular}{|c|c|}
\hline Mobile data traffic volume (TB, countrywide) & 114927 \\
\hline MNO's market share (\%) & 40 \\
\hline Traffic distribution among sites & $0.3^{\mathrm{a}}$ \\
\hline Traffic distribution for busy hour (over 24-hour period) & 0.1 \\
\hline Uplink to downlink ratio & 0.1 \\
\hline
\end{tabular}

2) Technology and spectrum related inputs - Technology definition and assumptions

TABLE A.3. TECHNOLOGY CONFIGURATION AND SPECTRUM ASSUMPTIONS

List of current and future network technology configurations:

GERAN 1: GERAN@900,GSM/EDGE

GERAN 2: GERAN@1800, GSM/EDGE

UTRAN 1: UTRAN@2100, HSPA+, R7, 21 Mbps

UTRAN 2: UTRAN@2100, HSPA+, R8, DC, 42 Mbps

UTRAN 3: UTRAN@2100, HSPA+, R10, QC, 84 Mbps

UTRAN 4: UTRAN@ 2100, HSPA+, R11, QC, MIMO 4x2, 336 Mbps

E-UTRAN 1: E-UTRAN@2600, LTE, 2x2 MIMO, 172 Mbps

E-UTRAN 2: E-UTRAN@1800, LTE, 2x2 MIMO, $172 \mathrm{Mbps}$

E-UTRAN 3: E-UTRAN@2600, LTE, 2x2 MIMO, LSA@2300, 344 Mbps

E-UTRAN 4: E-UTRAN@1800, LTE, 2x2 MIMO, LSA@ 2300, 344 Mbps

E-UTRAN 5: E-UTRAN@2600, LTE, 4x2 MIMO, 325 Mbps

E-UTRAN 6: E-UTRAN@1800, LTE, 4x2 MIMO, 325 Mbps

\begin{tabular}{|c|c|c|c|c|} 
Technology & $\begin{array}{c}\text { Cell spectrum } \\
\text { (Mhz)/Spectral } \\
\text { efficiency (bps/Hz) } \\
\text { / Data service } \\
\text { share }\end{array}$ & $\begin{array}{c}\text { Average } \\
\text { cell range } \\
(\mathbf{k m})\end{array}$ & $\begin{array}{c}\text { Current } \\
\text { territory } \\
\text { coverage } \\
(\%)\end{array}$ & $\begin{array}{c}\text { Typical } \\
\text { site } \\
\text { capacity } \\
\text { (Mbps) }\end{array}$ \\
\hline GERAN 1 & $0.95 / 0.4 / 0.25$ & 1.4 & 100 & 0.27 \\
\hline GERAN 2 & $1.18 / 0.4 / 0.25$ & 0.75 & 100 & 0.34 \\
\hline
\end{tabular}

\begin{tabular}{|c|c|c|c|c|}
\hline UTRAN 1 & $4.95 / 1.1 / 0.95$ & 0.65 & 5 & 14.8 \\
\hline UTRAN 2 & $9.9 / 1.3 / 0.95$ & 0.65 & 95 & 34.98 \\
\hline UTRAN 3 & $19.8 / 1.45 / 0.95$ & 0.65 & 0 & 78.03 \\
\hline UTRAN 4 & $19.8 / 1.75 / 0.95$ & 0.65 & 0 & 94.18 \\
\hline E-UTRAN 1 & $20 / 1.56 / 1$ & 0.5 & 22.24 & 89.26 \\
\hline E-UTRAN 2 & $20 / 1.56 / 0.95$ & 0.75 & 50 & 84.8 \\
\hline E-UTRAN 3 & $38 / 1.56 / 1$ & 0.5 & 0 & 169.6 \\
\hline E-UTRAN 4 & $38 / 1.56 / 0.95$ & 0.75 & 0 & 161.12 \\
\hline E-UTRAN 5 & $20 / 1.87 / 1$ & 0.5 & 0 & 107 \\
\hline E-UTRAN 6 & $20 / 1.87 / 0.95$ & 0.75 & 0 & 101.65 \\
\hline
\end{tabular}

3) Cost related inputs

TABLE A.4. COST OF RADIO ACCESS NETWORK ELEMENTS (CAPEX)

\begin{tabular}{|c|c|c|}
\hline \multicolumn{2}{|c|}{ Radio access network equipment and site types } & \\
\hline \multirow{3}{*}{ GERAN } & BTS & 30 \\
\hline & $\overline{B S C}$ & 350 \\
\hline & PCU & 100 \\
\hline \multirow{3}{*}{ UTRAN } & NodeB & 50 \\
\hline & NodeB upgrades & 10 \\
\hline & RNC & 1000 \\
\hline \multirow[b]{2}{*}{ E-UTRAN } & eNodeB \& new antenna system & 60 \\
\hline & $\begin{array}{c}\text { eNodeB supporting LSA }{ }^{\mathrm{a}} \& \text { new } \\
\text { antenna system }\end{array}$ & 37 \\
\hline MIMO & 4x2 MIMO antenna system & 12 \\
\hline \multirow{6}{*}{ Site types } & owned tower site & 50 \\
\hline & owned roof-top site & 25 \\
\hline & rental tower site & 50 \\
\hline & rental roof-top site & 25 \\
\hline & shared rental tower site & 16.7 \\
\hline & shared rental roof-top site & 8.3 \\
\hline \multicolumn{3}{|c|}{ 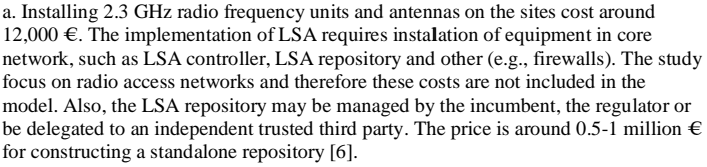 } \\
\hline
\end{tabular}

TABLE A.5. IMPLEMENTATION COST (IMPEX AS PART OF CAPEX)

\begin{tabular}{|c|c|}
\hline Network implementation actions & Action cost $(€)$ \\
\hline Site buildout ( $€ /$ site buildout) & 35000 \\
\hline NodeB upgrades ( $€ /$ NodeB upgrade) & 200 \\
\hline Other installation of components ( $€ /$ installation) & 500 \\
\hline
\end{tabular}

TABLE A.6. OPERATIONAL COST OF RADIO ACCESS NETWORK (OPEX)

\begin{tabular}{|c|c|c|}
\hline Category & Cost $(€)$ & Additional info \\
\hline rental tower site & 500 & \multirow{4}{*}{$\begin{array}{l}\text { - Site rental } \\
\text { - €/month/site }\end{array}$} \\
\hline rental roof-top site & 600 & \\
\hline shared rental tower site & 167 & \\
\hline shared rental roof-top site & 200 & \\
\hline Employees and salary & 4000 & $\begin{array}{c}-80 \text { employees in urban } \\
-€ / \text { month }\end{array}$ \\
\hline $\begin{array}{c}\text { Network operation \& } \\
\text { maintenance }\end{array}$ & 1 & $\begin{array}{c}\text { - sum of network components } \\
\text { (excluding sites) } \\
\text { - } € / \text { month/component }\end{array}$ \\
\hline Energy & 40000 & $€ / G W h$ \\
\hline $\begin{array}{c}\text { Administrative cost for } \\
\text { LSA }^{\mathrm{a}}\end{array}$ & 0 & $\begin{array}{c}\text { - } € / \text { month. Costs associated with } \\
\text { defining new rights and issuing } \\
\text { licenses }\end{array}$ \\
\hline
\end{tabular}

